\title{
Performances analysis of the reverse osmosis desalination plant of brackish water used for irrigation: Case study
}

\author{
Nada. El Harrak, Fatima. Elazhar, Abdel ali. Zdeg, Nourdine. Zouhri, Maryem. Elazhar, \\ Azzeddine. Elmidaoui.
}

Laboratory of Separation Processes, Department of Chemistry, Faculty of Sciences, Ibn Tofail University, Kenitra, Morocco

\section{Email address:}

azh80ar@yahoo.fr (F. Elazhar)

\section{To cite this article:}

Nada. El Harrak, Fatima. Elazhar, Abdel ali. Zdeg, Nourdine. Zouhri, Maryem. Elazhar, Azzeddine. Elmidaoui.. Performances Analysis of the Reverse Osmosis Desalination Plant of Brackish Water Used for Irrigation: Case Study. American Journal of Applied Chemistry. Vol. 1, No. 3, 2013, pp. 43-48. doi: 10.11648/j.ajac.20130103.12

\begin{abstract}
Desalinated brackish water is becoming an important water source for agricultural irrigation. In Brackish water desalination, pretreatment of reverse osmosis is the key step in designing the plants to avoid membrane fouling and scaling. It is enormously important to carry out a study designed at ensuring the optimization of the pretreatment system for brackish desalination plant in order to optimize the quality of the water fed through the reverse osmosis membranes, to guarantee the highest performance and to minimize the number of shutdowns for chemical cleaning. In this paper, performance evaluation carried out for a brackish water reverse osmosis plant for agricultural application, located in Dokkala Region in Morocco. This plant showed poor performances after few months of operating and frequent shutdown. The operating pressure increased significantly and the permeate conductivity decreased surprisingly. To identify the causes for the poor performance, different investigations were carried out. Thus, the pretreatment scheme was thoroughly reviewed to find out the causes of anomalies. The problem was resolved by removing chlorination and sodium bisulfate steps from the pretreatment.
\end{abstract}

Keywords: Reverse Osmosis, Desalination, Agriculture, Performances, Chemical Pretreatment, Cost

\section{Introduction}

Desalination is becoming an important source of drinking and agricultural irrigation water [1,2]. Desalination of brackish groundwater in some countries has a high potential in increasing the availability of water for agriculture, such as in Spain $22,4 \%$ of the total desalinated water is used for agriculture, because it offers a solution to the problem for long distance water transportation $[3,4]$. The cost of brackish water (BW) desalination is considerably lower about $35 \%$ comparing with the cost of seawater (SW) desalination $[2,5,6]$, making it more suitable for agriculture [3]. In addition, the use of desalinated BW in agriculture can potentially lead to increasing total biomass production [7] and also enables shifting from some types of crops to others, more salt sensitive and often more profitable [8].

The use of water for agriculture represents $70 \%$ of the global use of water and in developing countries the consumption of water in the agricultural sector exceeds $80 \%$ [9].The volume of desalinated water used for agricultural irrigation in countries such as Spain, Israel and the United Arab Emirates has dramatically increased in the last years $[9,10,11]$.

In Morocco, the percentage of the used water in agriculture exceeds the $75 \%$ [12]. The use of underground water in agriculture becomes frequently facing to the dryness of last the last decades. The use of underground water becomes frequent. This is the case in some regions in Morocco. However the salinity of much underground water exceeds the standards for irrigation of many crops and the use of this water resource without treatment decreases the yield of agricultural crops.

In this field, the big progress in Morocco in the water management since the beginning of the last decade is the use of desalination of brackish water, seawater, and water reuse for, irrigation, potable water and industrial units. Today the national desalination production capacity exceeds $50.000 \mathrm{~m}^{3} /$ day. The market of RO desalination 
was $43 \%$ in 2004 and is forecasted to increase up to $61 \%$ in $2015[14,15]$.

Many studies were carried out on the use of membranes process to treat the saline waters as sources of water for irrigation such as reverse osmosis, nanofiltration and electrodialysis. Table 1 gives the some investigations.

Table 1: Membranes process used for agricultural irrigation

\begin{tabular}{ll}
\hline Authors & Membrane process \\
\hline EL malki et al [12], Goodman et al [16] & Electrodialysis \\
Soliz et al [17], Shaffer et al [18], & Reverse osmosis \\
Mrayeda[19] & Nanofiltration \\
Mrayeda et al [19], Yan et al [20] & \\
\hline
\end{tabular}

In this study case, Doukkala is a plain stretching from the Atlantic Ocean south of Oum Er-Rbia River in Morocco, It is mainly an agricultural region, this activity occupies about $56,6 \%$ of the economy of this region. Doukkala region has a large capacity of groundwater, but the water quality is deteriorating due particularly to the saline intrusion. For this, the reverse osmosis is the used process to minimize the salinity of the saline water.

In this paper, performances analysis was carried out of desalination plant by reverse osmosis for irrigation, of a geranium flower kind, which is sensitive to saline water. The main objective is to identify the causes for the disorder of performances of the plant after one year of operation. For this aim, different investigations were proposed. In addition, the cost associated with the examined chemicals pretreatment options was evaluated.

\section{Methods and Materials}

\subsection{Raw Water Characterization}

The raw water coming from three wells (located at about $6 \mathrm{Km}$ from the sea) contains $2 \mathrm{~g} / 1$ of total dissolved solid predominantly chloride and sodium ions. The feed salinity varies during the seasons but never exceeds $4 \mathrm{~g} / \mathrm{l}$. The characteristics of raw water are given in table 2 .

Table 2: Characteristics of the raw water

\begin{tabular}{lcccc}
\hline & Well 1 & Well 2 & Well 3 & $\begin{array}{c}\text { Limits for } \\
\text { irrigation }\end{array}$ \\
\hline & & & & \\
Sodium $\left(\mathrm{Na}^{+}\right), \mathrm{mg} / 1$ & 406,25 & 261,73 & 338,45 & $<54,116$ \\
Potassium $\left(\mathrm{K}^{+}\right), \mathrm{mg} / 1$ & 2,24 & 1,30 & 2,53 & - \\
Magnesium $\left(\mathrm{Mg}^{2+}\right), \mathrm{mg} / 1$ & 144,6 & 131,43 & 226,32 & - \\
Calcium $\left(\mathrm{Ca}^{2+}\right), \mathrm{mg} / \mathrm{l}$ & 237,24 & 149,99 & 242,71 & - \\
Chlorides $\left(\mathrm{Cl}^{-}\right), \mathrm{mg} / 1$ & 1136,2 & 624,47 & 1134,91 & $<391,02$ \\
Sulfates $\left(\mathrm{SO}_{4}^{2-}\right), \mathrm{mg} / 1$ & 184,47 & 174,12 & 197,61 & 114,95 \\
Bicarbonate $\left(\mathrm{HCO}{ }^{-}\right), \mathrm{mg} / 1$ & 192,20 & 255,64 & 214,16 & - \\
Nitrates $\left(\mathrm{NO}_{3}{ }^{-}\right), \mathrm{mg} / 1$ & 200,08 & 237,53 & 241,65 & 103,32 \\
pH & 7,07 & 7,15 & 7,11 & 155,01 \\
Temperature, ${ }^{\circ} \mathrm{C}$ & 25 & 25 & 25 & - \\
TDS, mg/l & 2180 & 1515 & 2210 & $<1000$ \\
& & & & \\
\hline
\end{tabular}

\subsection{Description of the Reverse Osmosis plant}

The proposed design of the reverse osmosis unit is shown in figure 1.The main treatment unit is composed of:

- Pre-treatment post,

- Reverse osmosis group,

- Post-treatment.

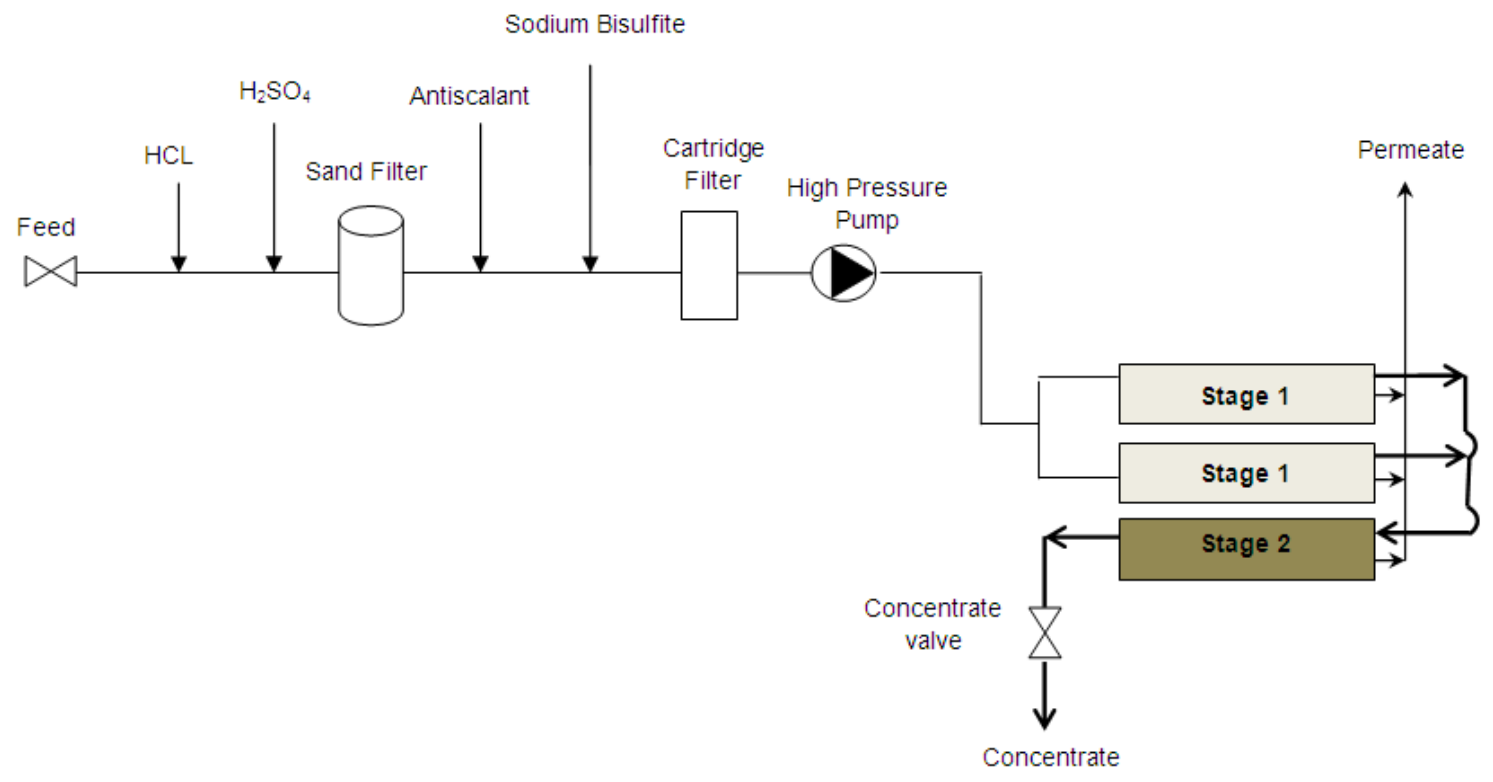

Figure1: Schematic diagram of $R O$ desalination process

\section{Pre-Treatment:}

The pre-treatment was designed to improve the raw water quality, to remove the undesirable materials in raw water, to provide a final protection and to adapt the pretreated water to the reverse osmosis membranes requirements [11]. Figure 1 shown the main steps of pretreatment, it includes:

- $\quad$ Dosage of 6-9 ppm of Sodium hypochlorite in order to control the membrane biofouling.

- Injection of Sulphuric acid $\left(\mathrm{H}_{2} \mathrm{SO}_{4}\right)$, in order to regulate the water $\mathrm{pH}$, about $62 \mathrm{ppm}$ of Sodium 
Metabisulfit $\left(\mathrm{NaHSO}_{3}\right)$ (reducing agent) to neutralize completely the residual active chlorine [21].

- Injection of a commercial scale inhibitor (antiscalant) with a dosage level at $9 \mathrm{ppm}$ in order to attenuate the risk of salt precipitations.

- The water undergoes a single sand filtration, in order to remove the solid particles and to protect the RO membranes from breakthrough particles.

- $\quad$ In the last step, a filtration with a cartridge filter is used for pretreatment sequence to remove particles larger than $5 \mu \mathrm{m}[22]$.

\section{Reverse Osmosis Unit:}

Table 3 gives the characteristics of Doukkala desalination plant.

Table 3: RO characteristics

\begin{tabular}{lll}
\hline Permeate Flow & $20 \quad\left(\mathrm{~m}^{3} / \mathrm{h}\right)$ \\
Concentrate flow & $12 \quad\left(\mathrm{~m}^{3} / \mathrm{h}\right)$ \\
Recovery rate & $63-65 \quad(\%)$ \\
High pressure & $13 \quad(\mathrm{bar})$ \\
Concentrate pressure & 8 & $(\mathrm{bar})$ \\
Number stage & 2 & \\
Number pressure vessel & 3 & \\
Number membrane/vessel & 6 & \\
\hline
\end{tabular}

\section{Post-Treatment:}

The Post-treatment step is limited to use the sodium hydroxide at level 6-9 ppm, in order to adjust the $\mathrm{pH}$ at value of 7 .

\subsection{Cleaning of Membrane}

The fouling of reverse osmosis elements is unavoidable with long-term operation. They can be fouled by biological matter, colloidal particles and mineral scale, element should be cleaned [20]. The protocol of membrane cleaning consisted of washing the membrane with several chemical solutions, it includes two steps:

Step 1: Alkaline solution, extremely effective against organic compounds.

Step 2: Acid solution, remove metal hydroxides, calcium carbonate, and other similar scales.

The consequence was the very high frequency of cleaning, as often as twice per month.

\section{Results and Discussion}

\subsection{Performances of Raw Water}

Figures 2, 3, and 4 present the daily variations of the Total Dissolved solids (TDS) collected from the tree RO feed well, during the year of 2011- 2012.

The results show that the Total Dissolved Solid (TDS) survey indicates that brackish water used to feed the RO plant, has a TDS approximately 1,20- 2,20 g/l, with a significant difference between all the seasons especially in the case of well 1 .

As showed in figure 2, in winter 2011 the feed water TDS was about $1,20 \mathrm{~g} / \mathrm{l}$, and gradually increased during the same year. Comparing with the same season but in 2012, the TDS of feed water from well 1, was the double value comparing with 2011. Moreover, there was no difference of reverse osmosis plant feed water TDS variation from 2011 to 2012 , in the case of wells 2 and 3.

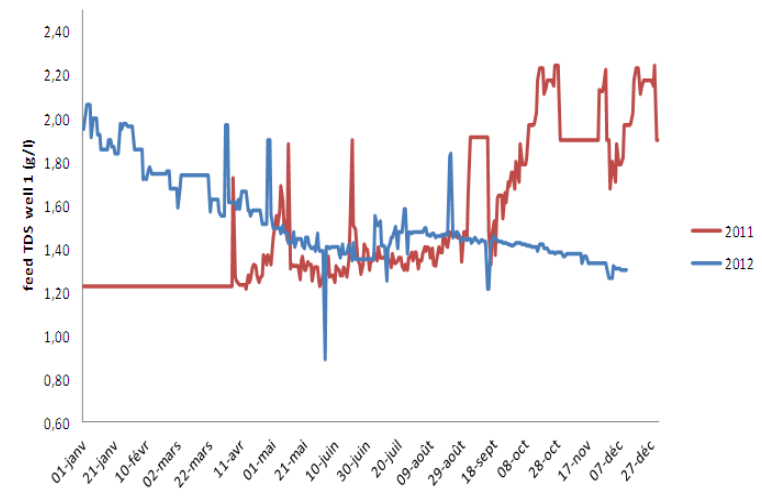

Figure 2: TDS well 1

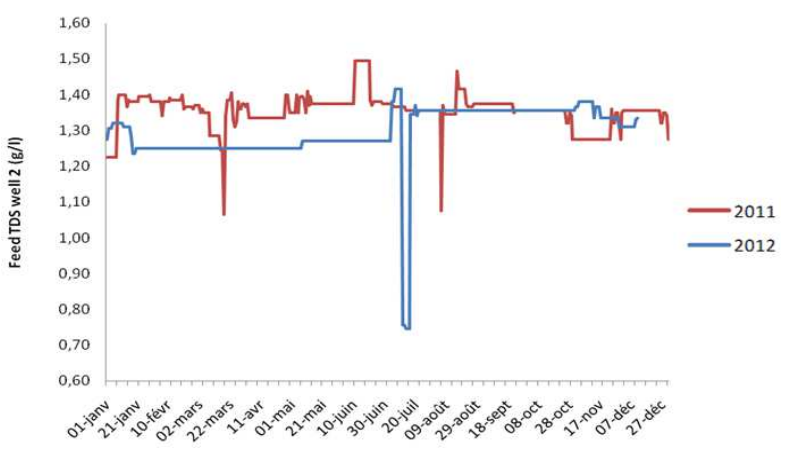

Figure 3: TDS well 2

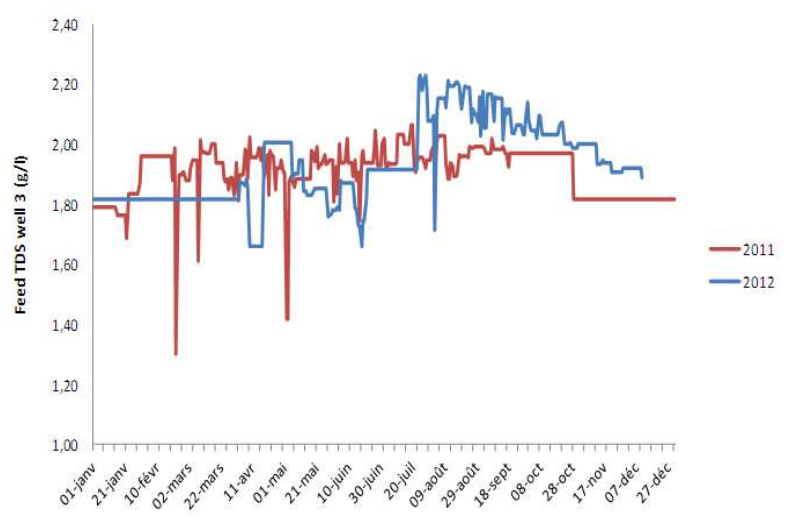

Figure 4: TDS well 3

\subsection{Performances of Reverse Osmosis Plant}

To optimize the reverse osmosis plant performances of brackish water desalination for irrigation. The TDS of producer water, the permeate flow, and feed pressure were controlled continuously. Figure $5(\mathrm{a}, \mathrm{b}$ and $\mathrm{c}$ ) shows the variation of these parameters versus time. 


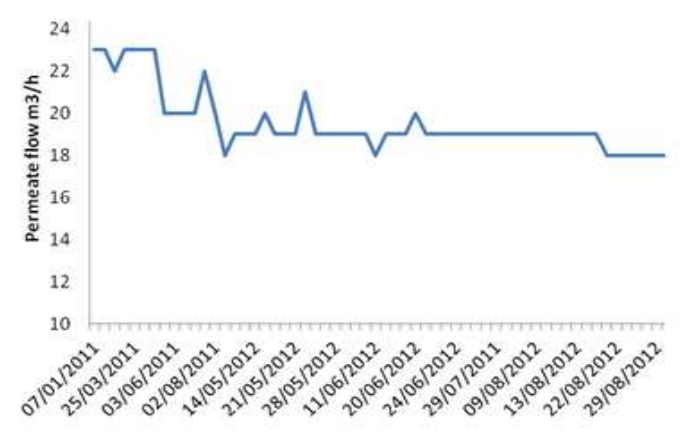

a. The permeate variation

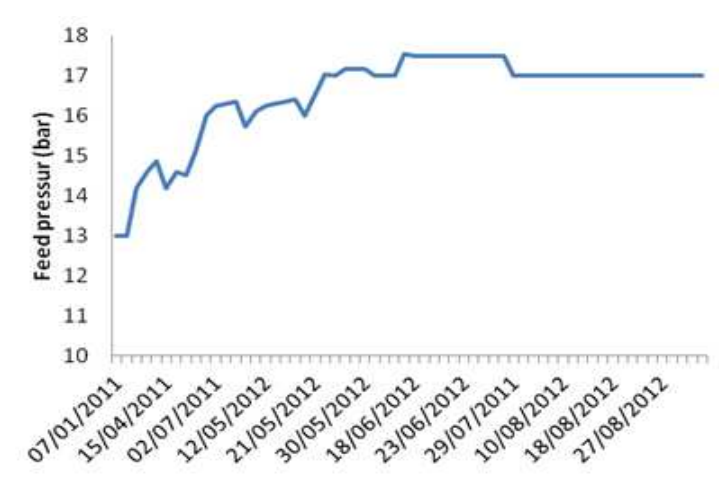

b. The Feed pressure variation

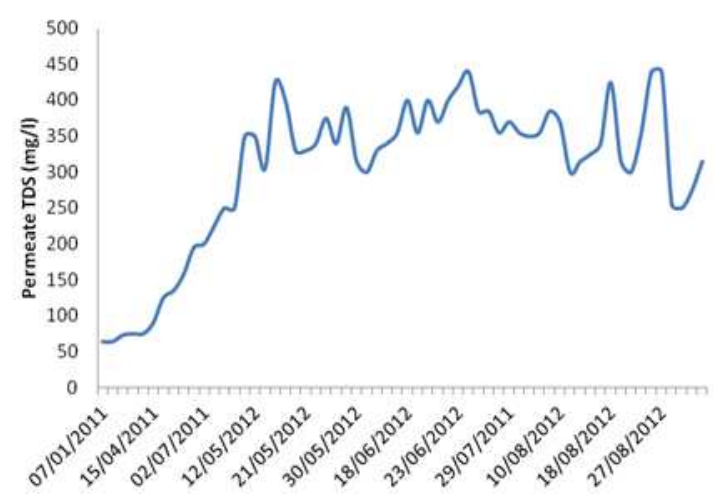

c. The permeate TDS variation

Figure 5: Performances of reverse osmosis plant versus time

The analysis of the results shows that the permeate flow decreases progressively with the increase of the feed pressure, and the produced water TDS increases from 70 to $350 \mathrm{mg} / \mathrm{l}$, the increases of the feed pressure was more significant from 13 to 17 bars.

The first investigation, indicated that it might be a seriously membranes fooling. For this reason it was appropriate to establish a cleaning protocol of the membranes, to remove the fouling aspect. The disfunctioning noticed was linked to biological activity as well as the presence of oxidizing agents in raw water. Furthermore, the use of prechlorination would have caused an increased oxidizing power of water by adding the residual chlorine.

In order to overcome the abnormal dysfunction of the RO plant and to remedy definitely the origin of this disorder, three actions were undertaken:

- Change the fouled membrane by osminics membranes AG8040F.

- Eliminate the chlorination step in pretreatment, to avoid the oxidation problem.

- Eliminate the sodium bisulfate from the pretreatment step, because it is used for the reduction of residual chlorine.

Figure 6 ( $a, b$ and $c)$ groups together the evolution versus time of measured parameters such as permeate TDS, feed pressure and product flow.
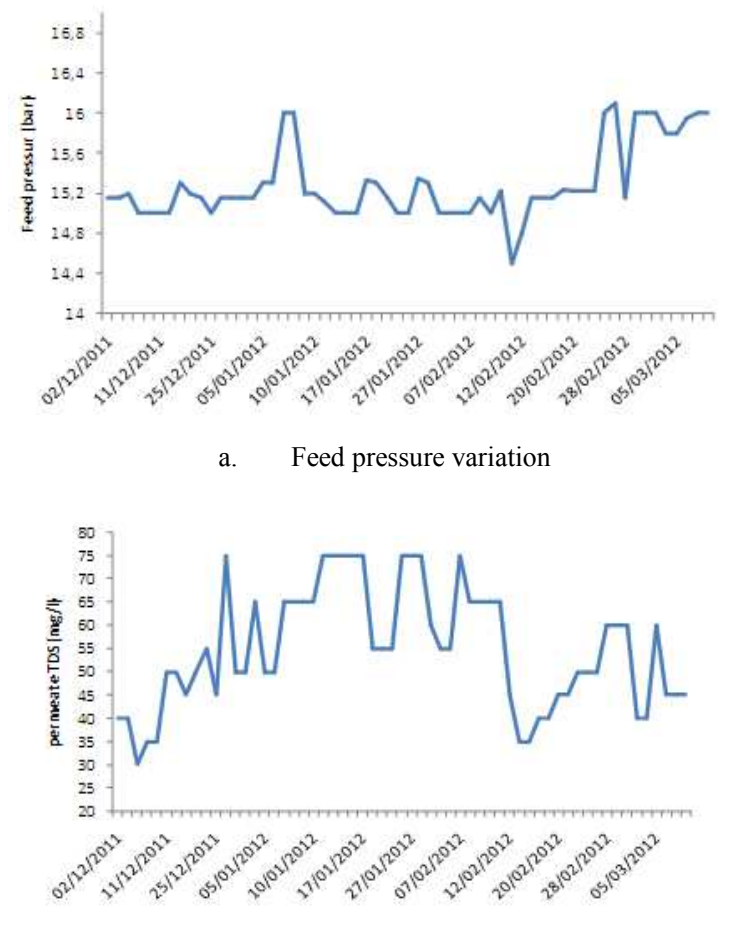

b. Permeate TDS variation

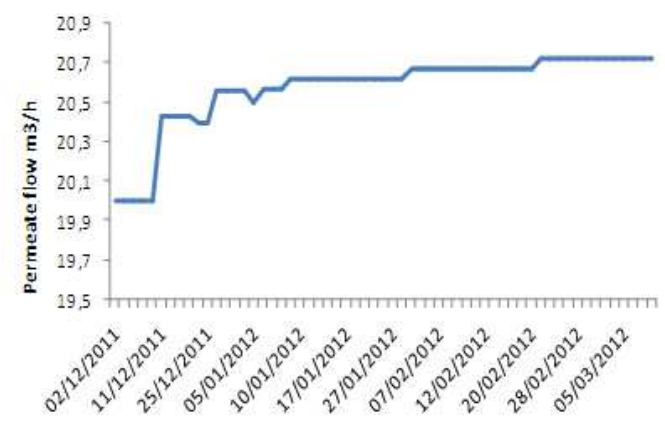

c. Product flow variation

Figure 6: Performances of reverse osmosis plant versus time

The results show that the evolution of the permeate TDS have been remained above the required values $75 \mathrm{mg} / \mathrm{l}$, with a feed pressure of 15 bar as recommended by the manufacturer of membranes. Also, the variation of the product flow was improved conforming to the characteristics of operation of the Doukkala desalination plant. 


\subsection{Economic Evaluation}

Several factors affect the cost of reverse osmosis desalination plant [23]. The total cost of the plant consists of two terms: capital cost and operation/maintenance cost [24]. The Capital Cost includes all expenditures associated with the implementation for construction (equipment, piping, service utilities, etc.), engineering efforts, and administrative/financing activities.

The Operation and maintenance (O\&M) costs consist of plant operation costs (energy, chemicals, replacement of consumables, and labor) and maintenance costs for plant equipment, buildings, and utilities. The O\&M costs are typically expressed as either all operational expenditures per year (e.g., \$/y) or operational costs for desalinated product water per volume (e.g., $\$ / \mathrm{m}^{3}$ ) [25].

In this study case and in terms of the economic point of view, economical evaluation was done concerning the chemicals cost. Table 4 gives the cost of chemical pretreatment. The remove of Sodium hypochlorite and sodium metabisulfite from pretreatment step, cause the saving cost of 54800 \$/year in operation unit cost.

Table 4: Cost of chemical pretreatment

\begin{tabular}{lll}
\hline Product & Cost $\$ / \mathbf{m}^{\mathbf{3}}$ & Cost $\mathbf{\$} \mathbf{y r}$ \\
\hline Sodium hypochlorite- $\mathrm{NaCl}$ & 0.30 & 50274 \\
Sodium Metabisulfit- $\mathrm{NaHSO}_{3}$ & 0.03 & 4570 \\
Antiscalant & 0.57 & 95297 \\
\hline
\end{tabular}

\section{Conclusion}

In reverse osmosis desalination technology, the steep of pretreatment of feed water is very important issue and is the key of the RO plants operation success. The operations of the pretreatment phase are more complicated when raw water quantity and quality changes during seasons. Thus the designed pretreatment became improper and not enough to secure RO membrane.

In this paper, the performance evaluation of a brackish water desalination plant used for irrigation was carried out. The poor performances of the plant were mainly due to the risk of membranes damage, by the effect of chlorine injection. After modification of chemical pretreatment steps by canceling the chlorine and sodium bisulfate, the plant showed stable performances. A new control system is applied in the plant to predict any futures anomalies.

Furthermore, it is also important to investigate the influence of this water on the soil and its effects on the crop yields.

\section{References}

[1] A. Ben-Gal, U. Yermiyahu, S. Cohen, Fertilization and blending alternatives for irrigation with desalinated water, J. Environ. Qual. 38 (2009) 529-536.
[2] L.F. Greenlee, D.F. Lawler, B.D. Freeman, B. Marrot, P. Moulin, Reverse osmosis desalination: water sources, technology, and today's challenges, Water Res. 43 (4) (2009) $2317-2348$

[3] J.M. Beltran, S. Koo-Oshima, FAO expert consultation on water desalination for agricultural applications, Rome (Italy), FAO Land and Water Discussion Paper, no.5, 2006, 60 pp.

[4] G.R. Lashkaripour, M. Zivdar, Desalination of brackish groundwater in Zahedan city in Iran, Desalination 177 (1-3) (2005) $1-5$.

[5] P. Glueckstern, M. Priel, E. Kotzer, Blending brackish water with desalted seawater as an alternative to brackish water desalination, Desalination 178 (1-3) (2005) 227-232.

[6] Y. Zhou, R.S.J. Tol, Evaluating the costs of desalination and water transport, Water Resour. Res. 41 (3) (2005) 3003/1$3003 / 10$.

[7] A. Ghermandi, R. Messalem, Solar-driven desalination with reverse osmosis: the state of the art, Desalination Water Treat. 7 (2009) 285-296.

[8] Z. Shimron, Economics of brackish and desalination water reuse for irrigation, Desalination 98 (1-3) (1994) 471-478

[9] UNEP 2002, Vital Water Graphics World Resources 200001,People and Ecosystems. The Fraying Web of Life, WorldResources Institute (ERI), Washington DC, 2000.

[10] A. Saadi, N. Ouazzani, Perspectives of desalination of brackish water for valorization in arid regions of Morocco. Desalination 165 (2004) 81)

[11] N. Prihasto, Q. Liu, S. Kim, Pre-treatment strategies for seawater desalination by reverse osmosis system. Desalination 249 (2009) 308-316.

[12] S. El malki, R.El Habbani, M. Tahaikt, M.Zeraouli and A. Elmidaoui, The desalination of salt water destine to irrigation by electrodialysis and its effects on the germination, growth and seed yield of wheat (Triticum durum Desf. Var. Karim). African Journal of Agricultural Research Vol.2. 041-046 (2007).

[13] A. Elmidaoui, Desalination and wastewater reuse, resources to be considered, Nato Security through Science Series, E: Human and Societal Dynamics, 12, IOS Press, 2006, pp. $185-187$

[14] F. Elazhar, N. El Harrak, A. Zdeg, M.El Amrani, M.Taky, A. Elmidaoui., Technical and economical comparison of the nanofiltration and reverse osmosis membranes in the brackish water desalination, Chemical technology An Indian Journal 7(2012), pp 29-33.

[15] Hyun-Je Oh, Tae-Mun Hwang, Sangho Lee, A simplified simulation model of RO systems for seawater desalination. Desalination 238 (2009) 128-139.

[16] B. Nigel, G. Russell, J. Taylor, Z. Xie , Y. Gozukara , A. Clements, A feasibility study of municipal wastewater desalination using electrodialysis reversal to provide recycled water for horticultural irrigation. Desalination 317 (2013) 77-83.

[17] D. Soliz, E. P. Glenn, R. Seaman, M. Yoklic, S. G Nelson, P. Brown, Water consumption, irrigation efficiency and nutritional value ofAtriplex lentiformis grown on 
reverse osmosis brine in a desert irrigation district. Journal of Agriculture, Ecosystems \& Environment 140, (2011) $473-483$.

[18] L. Shaffer, N.Y. Yip, J. Gilron, M. Elimelech, Seawater desalination for agriculture by integrated forward and reverse osmosis: Improved product water quality for potentially less energy, Journal of Membrane Science 415416 (2012).

[19] S.M. Mrayed, P. Sanciolob, L. Zou, G. Leslie An alternative membrane treatment process to produce low-salt and high-nutrient recycled water suitable for irrigation purposes. Desalination 274 (2011)144-149

[20] Y.A. Le Gouellec, M. Elimelech, Calcium sulfate (gypsum) scaling in nanofiltration of agricultural drainage water Journal of Membrane Science 205 (2002) 279-291

[21] A. Munoz Elguera, S. O. Pérez Bàez. Development of the most adequate pre-treatment for high capacity seawater desalination plants with open intake. Desalination 184 (2005) 173-183.
[22] I. Rirnhack N Voutchknv $\cap$ I ahav Desalination, Volume 273, Issue 1, 1 June 2011, Pages 6-22. Fundamental chemistry and engineering aspects of post-treatment processes for desalinated water-A review.

[23] F. Elazhar, M.Tahaikt, A.Achatei, F. Elmidaoui, M.Taky, F. El hannouni,I. Laaziz, S.Jariri, M. El Amrani, A.Elmidaoui. Economical evaluation of the fluoride removal by nanofiltration. Desalination 249 (2009) 154-157.

[24] S.A. Avlonitis, Operational water cost and productivity improvements for small-size RO desalination plants. Desalination, 142 (2002) 295-304.

[25] Young M. Kim , Seung J. Kim , Yong S. Kim , Sangho Lee, In S. Kim,Joon Ha Kim. Overview of systems engineering approaches for a large-scale seawater desalination plant with a reverse osmosis network. Desalination 238 (2009) 312332. 